\title{
Exploring Rural Contexts with Digital Storytelling
}

\author{
Donna G. Wake \\ University of Central Arkansas
}

This article describes rural middle school students' exploration of their identity and their rural contexts through the vehicle of digital storytelling. Participants included $407^{\text {th }}$ and $409^{\text {th }}$ grade students at two rural schools in the Southeast United States. Students worked in shared writing groups to create digital stories expressing their views on teen life in a small, rural town. The resultant stories were analyzed using comparative grounded theory yielding some themes which may be posited as unique to a rural population while other themes were typical of the developmental age regardless of geographical context. Study findings indicate that the rural nature of the participants' communities had a significant impact on their identity formation and understanding of community. This study supports students' use of technology to promote exploration of identity within geographic and sociological settings.

Keywords: digital writing; new literacies; place-based education; rural education

Rural schools occupy a unique sociological and historical niche in American education and represent the centers of their communities. These schools offer a place for social interaction and community renewal reproduction; they create a shared local identity and sense of place (Nitta, Holley, \& Wrobel, 2010; Schaftt, Alter, \& Bridger, 2006). Rural schools can unify the community and provide a sense of identity; they may work to build pride and a sense of place creating a more connected, thriving community. In this way rural schools are uniquely positioned to promote student identification with their community. However, rural schools may also alienate students from their surroundings by reinforcing negative stereotypes associated with rural communities and promoting the idea that leaving the community is the best path forward for those with the ability to do so (Corbett, 2009).

Unfortunately, education in these rural communities is often premised on a philosophy of loss. Kelly (2009) states:

Rural places, now more than at any other point in history, are places of great loss - of people, natural resources, and, often, as a result, any vision of long-term viability. In such places, loss as a persistent condition of life is vividly felt. ( $p$. 2).

Indeed, Corbett (2009) argues that formal education is "designed for those who leave" (p. 1), and this may cause significant tensions for students and families in these communities (Hardré, Sullivan, \& Crowson, 2009).

This study examines the use of digital storytelling with rural middle school students to promote their identity development and examination of community contexts (Corbett, 2009; Gruenewald, 2003).
Participants engaged in a shared authoring project where they created digital stories in small groups. These stories were then analyzed for themes, particularly those themes unique to rural contexts.

Thus, the significance of this study is in considering the students' unique perspectives as they worked to define who they were within their rural contexts and what those rural contexts meant to them. This paper examines issues associated with rural contexts and student identity development and describes the application of digital storytelling to support rural middle school students' exploration of identity and community.

\section{Education in Rural Contexts}

The term rural is being used in this study in alignment with the definition provided by the National Center for Educational Statistics (2007) publication Status of Education in Rural America. This document classifies communities as city, suburb, town, or rural with each context having several subcategories. The rural classification is defined by proximity to an urban-sized area and contains three sub-categories (fringe, distant, or remote) based on census data. The schools taking part in this study were classified as distant rural and remote rural. Distant rural communities are located more than 5 miles but less than 25 miles from an urbanized area. Remote rural communities are more than 25 miles from an urbanized area.

Despite the significant presence of rural schools in the national demographics, little research exists exploring education in rural contexts. While more than a third of all public schools and one-fifth of all students are considered rural (National Center for 
Educational Statistics, 2007), less than $6 \%$ of the research has focused on this population (Hardré, Sullivan, \& Crowson, 2009).

As noted above, rural schools offer a place for social interaction and community reproduction; these schools help create a shared local identity and sense of place (Nitta, Holley, \& Wrobel, 2010; Schaftt, Alter, \& Bridger, 2006). As a result of their central location in community, rural schools may work to strengthen community ties and unity. More likely, however, these schools may promote students' desire to disassociate from their local contexts resulting in an exodus of students from their communities once they are able to leave (Corbett, 2009; Kelly, 2009). Corbett (2009) states that in these communities "educational success equals leaving" (p. 4). This vision of schooling can cause dissonance among students, families, and community members resulting in a paradigm of loss (Hardré, Sullivan, \& Crowson 2009). Students may wish to move to more populated locales. Their families may feel conflicted when they realize that success means their students must leave. Alternatively, families may wish their students to remain closer to home and to build and strengthen the local community instead of potentially contributing to its demise (Corbett, 2009). Ironically, while educational success does result in students leaving their communities, these communities need welleducated members in order to prosper. These communities cannot afford for students to see their formal school career as either disconnected or as a vehicle for leaving (Corbett, 2009).

These conflicting beliefs can lead to ambivalence in the community about the value and outcomes of formal schooling. Formal education may be seen as a threat to the community causing its youth to leave. On the other hand, for those who stay, formal education may be viewed as irrelevant or useless as it does little to promote local values and issues (Corbett, 2009). This is particularly true in the current culture of standardized accountability which promotes curricula that functions independently of the place where it is implemented. In this way, education works to transmit a dominant culture viewing non-standard populations as the "other" (Corbett, 2009; Gruenewald, 2003).

The departure of students from small communities impacts community sustainability. For example, school consolidation is a very real threat in many small, rural communities. The consolidation of rural schools may cause communities to lose sense of place and identification resulting in a loss of community unity (Graves, 2010). Consolidation can have a profound impact on remaining students and families in the form of decreased funding and resources. Specific effects of consolidation may include increased transportation (time and funding), decreased graduation rates, and higher drop our rates (Howley \& Howley, 2006).

\section{Place-Based Education}

While formal education may be viewed as detrimental or foreign in rural communities, rural education can be reconceived as a way to contribute to a sense of community pride and unity. Education takes place in a specific socio-cultural context, and formal education as it is currently conceived may not be an appropriate vehicle to use in a setting where the economic, cultural, and social capital networks are highly localized (Corbett, 2009). Kelly (2009) posits that formal education could be used to promote community solidarity for rural students and argues that rural communities are sustained by a deep knowledge of time and place.

This specificity of time and place accentuates the need to center educational practice in a specific sociocultural setting so that students can explore identity, place, and their interconnection (Kelly, 2009). In other words, rural students can see their communities as a source of strength and pride. The benefits of rural contexts can be highlighted and promoted as a resource for students and families with unique attributes not shared with suburban and urban settings.

Gruenewald's (2003) critical pedagogy of place describes an approach to education that is reliant on the physical community and asks students and teachers to reflect on their work in relation to the unique places they inhabit. Even rural communities cannot be regarded as uniform. Instead these communities represent unique, multiple, and distinct places (Corbett \& Vibert, 2010). In other words, the work of education must consider and reflect the local contexts of the school. This approach to education is experiential and aligns curriculum and assessment to location (Corbett, 2009). Educators are challenged to reflect and to connect their instructional work to the places and spaces where they practice or "inhabit" while using strategies aligned with constructivist and democratic practices (Gruenewald, 2003).

Finally, while the local aspects of place should be used as a basis for education, an approach that focuses solely on local contexts in a manner that overinflates the local community (e.g. "our town is the best") can be just as damaging as an approach that promotes disassociation from place. A naïve perspective on community can result in a passionate attachment to place which may lead to unexamined myths about 'a way of life' and an unquestioned acceptance of social hierarchies. This view of community is no more liberating than disassociation or an attitude of resignation toward leaving (Kelly, 2009, p.3).

In other words, the rural community must not be idealized and inflated in the minds of the learners. 
Rather, it must be analyzed critically and considered realistically.

\section{Student Identity Development}

Adolescents are occupied by attempts to define identity (Erikson, 1979; Kroger, 2003, 2006; Meeus, Iedema, Helson, \& Volleberg, 1999). In this case, the identity formation process is defined by the rural contexts of the students involved. As these students actively engage in the search for their identity, they seek independence and an identity separate from their family, and perhaps community, context. Students may "try on" different identities, take part in different activities, and assume different behaviors. In addition, the peer group becomes the most important reference point, and adolescents may connect with different friends and peer groups as they attempt to define "who they are" in relation to others around them. Part of this process includes formulating a philosophy of life. Often these philosophies are based on ideals rather than a sense of concrete reality. Thus rural students may seek to experiment with or "try on" identities different than those of their lived experiences.

Those students who receive support and encouragement in the identity formation process will successfully establish a strong sense of self. They will become independent and will develop a feeling of control over their actions and options. Those who are not able to successfully navigate this stage of development will remain insecure and confused about themselves and the future (Erikson, 1979).

Regardless of environment, students' attempts to define identity are impacted by their school and community environments. Students moving through this stage in rural contexts may feel pride and a close sense of identification with these settings (Kelly, 2009). On the other hand, they may feel disassociated or unconnected from their rural surroundings (Corbett, 2009) and may attempt to redefine themselves using some real or perceived indicator of a more suburban or urban environment. For example, a student may attempt to take on an identity like goth or emoidentities that have their origin in urban cities. Conversely, those students who enthusiastically assume the rural identity may be forming an unexamined, zealous attachment that may limit opportunity and perspective (Kelly, 2009).

The process of adolescents' identity formation that involves self, social, and environmental identities strongly connected to place is aligned with the tenets of place-based education (Gruenewald, 2003). Yet this process may also work to position individuals differently within the rural context and potentially lead to tensions and resistances. Corbett (2009) found that social class and gender did influence students' specific socio-spatial identities within their rural community in terms of access to resources and likelihood of remaining in or leaving the community. Those with the ability to leave may feel compelled to do so, while those who stay are somehow viewed as deficient or incapable of "making it" in the world outside their rural community (Corbett, 2009). Students may align themselves with and against each other based on these views, which further impacts their identity formation process.

\section{Technology in Rural Contexts}

While minimal educational research focuses on rural contexts (Hardré, Sullivan, \& Crowson, 2009), even less of this research focuses on the use of technology in rural school contexts (Miller, 2010; Schaftt, Alter, \& Bridger, 2006). Furthermore, few studies focus on using technology to promote student exploration of identity within their geographic and sociological settings (Corbett \& Vibert, 2010).

Rural communities also are associated with uneven educational development and opportunity, particularly in the face of globalizing influences brought about by technology advancement (Gruenewald, 2003). In school contexts, technology is seen as a source of necessary $21^{\text {st }}$ century literacy skills regardless of income, language, or geography. Rural schools can use technology to provide students with options, experiences, and resources equivalent to their urban and suburban counterparts (Hawkes, Halverson, \& Brockmueller, 2002; Miller, 2010; Schaftt, Alter, \& Bridger, 2006). Technology can be used to promote students' critical analysis of a topic and to support students' expression of their own perspectives and voice.

Encouraging students to explore identity with a conscious and critical awareness of their rural contexts may aid their development of identity and voice (Corbett \& Vibert, 2010; Wood \& Smith, 2010). Technology can be used to support students' analysis of identity and community to allow for greater perspective in comparing rural contexts to other environments; this may work to reduce bias and stereotype and/or idealization of one context over another (Kelly, 2009). Technology can also be used by students to express their perspective and as an outlet for student voice. For these reasons, and given the research of Corbett (2009) and Gruenewald (2003) on place-based education, technology was seen as central to this study and a source of relevance to the field. 


\section{Digital Storytelling}

Digital storytelling is one form of digital writing and was chosen as the vehicle for the students' exploration of identity and context in this study. Whereas digital writing encompasses all forms of writing supported by technology (e.g., tweeting, blogs, social networking, word processing), digital storytelling is a specific digital writing application. The final product of this type of writing is a digital story - in essence, a small movie containing still images, voiceover narration, and music if desired (Center for Digital Storytelling, 2010). Digital storytelling, then, is the act of writing and producing the digital story.

In digital storytelling, the writer weaves narrative, images and audio together using common, technologybased platforms (Center for Digital Storytelling, 2010). Educators view digital storytelling as a powerful means for promoting literacy with adolescents (Ohler, 2008) as these learners are surrounded by visual and media influences that work to predispose and motivate them to digital writing (DeVoss, Eidman-Aadahl, \& Hicks, 2010; Kajder, 2010).

Digital storytelling has been recommended as a vehicle for teaching skills in multiple content areas and in multiple literacies (O'Brien, \& Scharber, 2008). As such, digital storytelling is one means of promoting a place-based or place-conscious curriculum which allows students to explore identity and community through technology supported literacy. Gruenewald's (2003) place-based education approach aligns with the New Literacy Studies which positions literacy as a socially situated practice (Cope \& Kalantzis, 2000; Gee, 2000; New London Group, 1996). In this perspective literacy is defined as something broader than traditional print-based media and instead looks at the variety of expressive and communicative means available and allows students to explore that which defines them socially, culturally, and emotionally.

\section{Research Questions}

The research questions for the study are: (a) What factors influence rural adolescents' perceptions of identity as revealed in their digital stories?

(b) What factors influence rural adolescents' perceptions of their communities as revealed in their digital stories?

(c) How does rural adolescents' use of technology support their examination of identity and context?

\section{Method}

This study used a qualitative research paradigm in seeking to understand the meaning-making efforts of the participants. A qualitative approach is well-suited to examining a topic where little research has previously been conducted or where the researcher does not know the important variables to examine (Creswell, 2002). The views of rural adolescents of their identities and contexts have received modest attention in the research base, and this makes qualitative inquiry an apt fit for this research study.

In this phenomenological approach, information is gathered first-hand through personal interaction with the participants. Underlying assumptions in this approach are that knowledge is socially constructed through interaction within a community and that individuals seek to make sense of their world through experiences and interpretation.

Data gathered through these interactions is interpreted through induction and is, in part, shaped by the researcher's own experiences and background (Bogdan \& Biklen, 2003; Creswell, 2002). The researcher's role in this type of research is to have sustained, intensive engagement with the participants. In this study, engagement occurred as the researcher supported the students in crafting and refining their stories. Due to the fact that the researcher is implicitly involved in the research process, the act of interpreting the resultant data may include biases, values, and interests from the researcher's own "personal, cultural, and historical experiences" (Creswell, 2002, p. 9). When possible, these personal perspectives are indicated in the results and discussion sections of this study.

Specifically, this study employed a grounded theory methodology wherein theory is generated or "grounded" in the views of the participants (Bogdan \& Biklen, 2003; Glaser \& Strauss, 1967; Strauss \& Corbin, 1990; Strauss \& Corbin, 1994). In this approach, theory is derived from the views of the participants in the study through multiple stages of data analyses involving coding, refinement, and interrelationship of categories within the data which are constantly compared to the emerging categories of reveal patterns and themes leading to hypothesis formation. The goal of this type of research is to focus on the participants' views which are collected in the form of open-ended, emergent data (Creswell, 2002); the emergent data collected in this study were the narratives created by the adolescents in forming their digital stories. The multiple meanings provided by the individual participants' experiences, defined by historical and cultural norms, lead to a theory or pattern. 


\section{Participants}

Participants in the study included eighty $7^{\text {th }}$ and $9^{\text {th }}$ grade students at two rural schools. Forty of the participants were $9^{\text {th }}$ grade students attending a midsized rural junior high in one Southern community. This group participated in the project in late spring 2009 . Forty of the participants were $7^{\text {th }}$ grade students attending a small rural middle school in a second Southern community. This group participated in the project in fall 2010.

Participants at the first school included 21 females and 19 males ranging in age from 14 to 16 years. Eleven of the students were of Hispanic or Latino ethnicity with two identified as English second language learners; 29 participants were Caucasian or White/non-Hispanic. Twenty-one of the participants were eligible to receive free or reduced price lunch. Seventy-three percent of the participants at this location had achieved proficient or advanced on their yearly, state-mandated benchmark exams in literacy. None of the participants were identified as having a disability that would interfere with their ability to take part in this project.

Participants at the second school included 22 females and 18 males ranging in age from 11 to 13 years. Three of the students were of AfricanAmerican descent; the remaining 37 participants were Caucasian or White/non-Hispanic. Within this participant pool, there were no identified English language learners. Twenty-three of the participants were eligible to receive free or reduced lunch. Sixtytwo percent of the participants at this location had achieved proficient or advanced on their yearly, statemandated benchmark exams in literacy.

The age of student was particularly relevant for inclusion in this study due to their need to explore issues of identity in relation to their stage of development. These students' exploration of identity was seen as intertwined with their local contexts thus providing a window into these learners' unique experiences and perspectives in their rural communities.

Participants were selected as they were enrolled in their required English coursework at their respective schools. Both teachers involved in the study felt that their students needed an authentic, expository writing experience and felt that the end-product of the digital story would motivate students to write. Authentic writing is defined as writing with a real audience and purpose in mind - not writing for a contrived reason (i.e. for testing purposes) or for a limited audience (i.e. the teacher, test reviewers). An authentic audience is comprised of people genuinely interested in the writing topic who will be likely to listen, respond, and attach value to the writing.
Based on discussions with the teachers, it was clear that neither student population had previous authentic writing experiences in these classrooms. The literacy curriculum at both schools was largely driven by the state-mandated frameworks and testing requirements focusing primarily on grammar instruction, vocabulary, comprehension strategies, and responding to writing prompts. Understandably, both teachers had focused their writing instruction on benchmark exam preparation where students wrote to contrived prompts for an audience of the teacher and unknown test reviewers. This is aligned with the findings of Corbett (2009) and Gruenewald (2003) who warn against the limiting influence of standardized curriculum and accountability in education.

The two schools were located in communities approximately 75 miles from each other. The first community was identified as a remote rural school (more than 25 miles from an urban area); the second community was identified as a distant, rural school (more than 5 and less than 25 miles from an urban area) (National Center for Education Statistics, 2007). The socioeconomic profiles of both districts indicated that over half of the student population was eligible for free or reduced lunch status.

These schools had limited technology available to the students. A technology survey completed by the classroom teachers showed that each classroom included only one master classroom computer with internet access and a classroom smart board. The teacher at the first school site used the smart board to project the daily bell ringer, to diagram sentences, and to project workbook pages. The teacher at the second school did not use the smart board regularly in the classroom. Neither school offered a technology curriculum; however, participants at the second location were required to take a keyboarding course. Neither teacher involved in this study had previously used technology to support their students' literacy efforts due to a reported lack of resources and professional support.

\section{Research Design}

Participants at both locations were led through an identical process overseen by the researcher. The adolescents in the study were guided to create a digital story exploring their lives as teens in the rural south. The teachers' and researcher's role in the process was to guide and provide support.

On the first day of the project, students were placed into heterogeneous groups of 4-5 students, predetermined by the classroom teachers. The group structure was chosen by the researcher and teachers for two reasons. First, the use of groups supported the 
idea that knowledge is socially constructed. The researcher and teachers felt that the group structure would promote diversity of viewpoint and opinion. The process of negotiating the story within the group would also require students to fully explore and analyze the content they chose to include and the structure of their stories. Second, since access to technology was limited, it was felt that groups would be a more efficient way to approach technology integration.

The groups were monitored closely by the researcher and teachers for group processing. It was important to all involved in the project that the students handle as much of the process as independently as possible. Groups wrote contracts on the first day of the project delineating each member's roles and responsibilities. The group members also peer-evaluated each other at the conclusion of the project, and the peer-evaluation rubric was shared on the first day as well. Conflicts among the group were expected to be mediated by the group members with the researcher and teachers called into assist when needed.

To begin the process, the participants were then given the prompt: "If you could tell the world about what life as a teenager in (name of town) is like, what would you tell them?" Participants were provided with chart paper and markers and supported in the brainstorming process. The groups also were told that the final day (day 6) of the project included a public showing of their work, thus establishing the identity of an authentic audience. The students were also shown several examples of digital stories so that they would understand the goal of the end product.

On the second and third days of the project, student groups were invited to refine their initial brainstormed ideas and to start a rough draft of their story script. Again, they were given large chart paper for brainstorm maps and their initial drafts. This part of the process was the most labor-intensive as the student groups had to negotiate and navigate the group process in order to write the drafts. The initial drafts were hand-written due to the lack of available technology.

On the fourth and fifth days, the students added images, voice, and music into their digital story. Groups staged and photographed their own visuals with the use of digital cameras and their phones. Alternatively, they found images on the internet which they emailed to the researcher for approval and inclusion. Students also began to rehearse their scripts and to search for appropriate music for inclusion.

Note that the teachers and researcher introduced the concept of visuals and audio late in the process as they felt that introducing these components too early in the process might distract students' from the writing process. Introducing visuals and audio later in the process also compelled students to revisit their stories for further development and revision.

Beginning on the sixth day, with the assistance of the researcher, the students began to build their stories in Microsoft Photostory 3. Some students worked in small groups with the researcher while other groups continued to revise and edit their writing. Both sites used only one laptop containing a copy of Microsoft Photostory 3. The researcher sat with the student groups showing them the software and aiding them in their design and production of the stories.

Finally, students at both locations held viewing parties showcasing their work to their peers, administration, teachers, and parents. This event was always a planned aspect of the curriculum and used as a way to communicate to participants the idea of an authentic audience. Eighteen stories were produced across the two school sites - nine at each location.

\section{Data Analysis}

Qualitative research focuses on describing rather than explaining an event or situation. Researchers using qualitative approaches make interpretations and form a conceptual schema based on their observations of the data (Bogdan \& Biklen, 2003). Grounded theory, sometimes called comparative grounded theory, is a qualitative method that emphasizes the generation of theory from data in the process of conducting research. This approach requires the researcher to analyze data through four stages: coding, creating of concepts (groups of similar codes), creating of categories (groups of similar concepts), and developing theory generation or explanation (Glaser \& Strauss, 1967; Strauss \& Corbin, 1990; Strauss \& Corbin, 1994).

The patterns noted in the data lead to the identification of general concepts about the observed phenomenon. These concepts contribute to identification of broader theoretical positions that can be replicated and/or tested through comparison with other groups. According to Glaser and Straus (1967), theory generation does not require a large number of cases; rather, the researcher's task is to develop a theory from the data that are collected on the relevant behavior. Thus, the small population size in this study is conducive to this methodology.

The validity of qualitative research is important to verify and should be considered to substantiate the accuracy of the findings, particularly as the act of interpreting the resultant data may be shaped by the researcher's background and how the researcher is positioned in the research. In this case, the study findings were corroborated through the use of rich, thick description in an attempt to convey the focus of 
the study and the essence of the participants' perspectives around the central topic. Included in this description is mention of any bias the researcher brought to the study. This strategy provides a framework for others interested in transferability and comparison. In addition, a peer reviewer experienced in narrative inquiry was used to verify the research design and findings (Creswell, 2002). Using these strategies supports the credibility and dependability of the data findings.

\section{Data Sources}

The student-produced digital stories were the sole data source for this study. The students' stories were analyzed using grounded comparative analysis describing reoccurring codes, concepts, and categories. Initial themes were established during the first and second combings of the transcripts. All statements that did not fit the initially-defined themes were examined in a third combing of the scripts; they were either incorporated into an existing category or a new category was created for their placements. The scripts were examined two more times by the researcher to eliminate errors in the coding and to combine or collapse existing concepts and categories into broader or more clearly defined categories.

An objective rater, a literacy education specialist, checked the scripts and codes to establish inter-rater reliability. The researcher and objective rater used joint-probability of agreement to examine the data with the benchmark of $100 \%$ agreement.

\section{Procedures}

The initial thematic coding of the student stories involved 329 separate idea units (120 from the first community and 209 from the second community) which were assigned numeric codes. The stories were coded for discrete idea units: a clause including any verb and the elements that cluster with it (Gee, 2005). Each idea unit received a numerical, coded assignment. Coded idea units were grouped into concepts and, subsequently, into categories. For example, the first code to emerge from an idea unit was related the importance of sports in student role identification - "I play football;" this idea unit received a numeric code of "1". Any subsequent idea unit that mentioned football in relation to role identity also received a code of " 1 ". Other idea units that mentioned sports received separate codes and were identified as related concepts.
The 329 separately coded idea units were collapsed into fifteen dominant concept families. For example, all sports-related idea units were grouped into a concept family labeled "sports and identity." Finally, the concept families were grouped to reflect larger categories. In this instance, "sports and identity" was placed under the "facts about teenagers" category.

Four categories emerged from the coding of the data: facts about teenagers ( 8 concept families, 21 codes); facts about friends and peers ( 2 concept families, 2 codes); facts about the school ( 2 concept families, 6 codes); facts about community ( 2 concept families, 4 codes). These categories were aligned with the project prompts provided to the students as a catalyst for student brainstorming and may reflect a bias of the researcher in designing the study and interpreting the results.

A simple percentage was calculated to represent the number of comments made within each category and to the number of overall comments. The data were also disaggregated in order to assess any differences between sites keeping in mind that even rural communities cannot be regarded as uniform (Corbett \& Vibert, 2010). There were no significant differences between the population groups in the coding. Thus, further discussion of community differences will be limited.

Codes seen as rural were noted by the researcher in the data coding process based on the bias of the researcher. The researcher felt secure in identifying "rural" themes based on extensive teaching experiences in both rural and urban settings. While the researcher does not wish to be reductionist in labeling certain markers as "rural", these markers may yield greater insight into the identity formation of rural adolescents.

\section{Findings}

This section contains data about the categories, concepts, and codes, with specific examples detailed in tables 1-5. The subsequent discussion section will analyze themes and categories unique to these adolescents' identity exploration within their rural environments. As shown in Table 1, four categories emerged from the coding: (a) facts about teenagers/role identification $-62 \%$, (b) facts about friends/peers $-12 \%$, (c) facts about school - $20 \%$, and (d) facts about community $-12 \%$. 
Table 1

Thematic Categories, Concepts, and Codes

\begin{tabular}{lcccc}
\hline \multicolumn{1}{c}{ Categories } & Concepts & Codes & $\begin{array}{c}\text { Total } \\
\text { Comments }\end{array}$ & Percentage \\
\hline Facts about Teenagers & 8 & 21 & 203 & $62 \%$ \\
Facts about Friends & 2 & 2 & 39 & $12 \%$ \\
Facts about School & 2 & 6 & 67 & $20 \%$ \\
Facts about the Community & 2 & 5 & 40 & $12 \%$ \\
\hline
\end{tabular}

\section{Facts about Teenagers and Role Identification}

The category that received the most comments in the digital stories reflected the adolescents' attempts to describe their identity as teenagers. Sixty-two percent of all comments fell in this category with 8 concept families and 21 distinct codes. Prevalent concepts in this category included: recreational activities, role identification, use of technology, friends and family, food, and pets/livestock (see Table 2). These comments overwhelmingly represented the participants' attempts to identify, define, and explain their identity for themselves, for their peers, and for a larger external audience. This effort to define 'self' is aligned with the developmental needs of this age of student (Kerpelman, Pittman, \& Lamke, 1997; Kroger, 2003, 2006; Meeus, Iedema, Helson, \& Volleberg, 1999).

Recreational activities that defined what teens $d o$ made up $26 \%$ of the overall comments in this category. These activities focused on what teens did for fun and included sleeping, watching TV, listening to music, going to the movies, shopping, and participating in outdoor activities (hunting, fishing, 4wheel driving). These activities also were heavily couched in relations and communications with their peer groups as many of these activities involved interacting with their friends - e.g., going to the movies with friends. The researcher's observational notes indicated that the activities participants mentioned correlated with gender divisions; males noted outdoor activities as important and females noted movies and shopping as their preferred recreation.

After recreation, the next prevalent theme emerging from the data in this category was role identification (22\% of all comments in this category). These comments included participants' references to themselves in relation to an identity definition. In this theme, labels abounded (e.g., - jock, redneck, goth, cheerleader, smart kid, in the band, play softball). Note that some labels are rural while others reflect a more urban vibe; this will be explicated in the discussion.

Technology was the next dominant category with $21 \%$ of all comments reflecting these adolescents' use of various technologies. The comments discussing technology largely focused on use of technology for social networking. These teens saw themselves as technology users with technology being a large part of what teens do and who they are. They noted the importance to their lives of texting, using the internet for research, using facebook, and gaming. Texting friends was the leading code within this category carrying $48 \%$ of the technology related comments overall. The next categories to emerge from the data were the teens' recognition of friends $(10 \%)$ and family (4\%) in their work to define identity. The mention of friends in this regard was coded differently than the participants' comments describing friends and peers (discussed in the next category). Comments in this concept family focused on adolescents' needs to connect with friends and family as part of what teens do (e.g., hang out, talk on the phone, text, spend time with friends) and who they are. It was not surprising that mention of friends was more prevalent than mention of family. This is in fitting with the research on teens and identification with peer groups regardless of the environment (Kroger, 2003, 2006; Meeus, Iedema, Helson, \& Volleberg, 1999).

Food was the next dominant concept with $7 \%$ of comments in this category. Here participants noted eating and eating with friends as something teens $d o$. Finally, mention of pets/livestock was a strong concept in the coding (5\%) with the participants mentioning animals in relation to their identity (e.g., I ride horses, llamas are my favorite animal) and making note of animal-related chores as part of what teens do (e.g., we check chickens for eggs). 
Table 2

Thematic Categories, Concepts, and Codes Reflecting Facts about Teenagers

\begin{tabular}{|c|c|c|c|c|}
\hline Concepts & $\begin{array}{l}\text { Code } \\
\text { Families }\end{array}$ & Example Coded Statements & $\begin{array}{c}\text { \# of } \\
\text { Occurrences }\end{array}$ & $\begin{array}{c}\% \text { in } \\
\text { Category }\end{array}$ \\
\hline \multirow[t]{7}{*}{ Recreation } & Sleep & We like to sleep & 3 & $26 \%$ \\
\hline & $\mathrm{TV}$ & Mostly we watch TV & 9 & \\
\hline & Music & Most of us rock out to music & 9 & \\
\hline & Movies & We like going to the movies & 3 & \\
\hline & Shopping & You can shop at Wal-Mart & 4 & \\
\hline & Outdoors & $\begin{array}{l}\text { On weekends, we hunt deer, dove, and } \\
\text { turkey if the seasons are open } \\
\text { We also do a lot of your four-wheeling } \\
\text { We do dirt bike racing }\end{array}$ & 11 & \\
\hline & Other & $\begin{array}{l}\text { We like to read } \\
\text { We do chores }\end{array}$ & 10 & \\
\hline \multirow{13}{*}{$\begin{array}{l}\text { Role } \\
\text { Identification }\end{array}$} & Sports & I am a jock & 27 & $22 \%$ \\
\hline & & The sporty kids rule & & \\
\hline & & Preppy cheerleaders are the best & & \\
\hline & Arts & $\begin{array}{l}\text { There are some kinds in the band } \\
\text { Some kids are into art }\end{array}$ & 13 & \\
\hline & "Smart" & There are smart kids & 2 & \\
\hline & & You can participate in G.T. & & \\
\hline & Other & There are cool kids & 2 & \\
\hline & & There are rednecks & & \\
\hline & & There are wimpy kids & & \\
\hline & & I am a goth & & \\
\hline & Texting & We like to text & 20 & \\
\hline & & Cell phones are genius & & \\
\hline & & My phone is on vibrate so I can text & & \\
\hline \multirow[t]{4}{*}{ Technology } & Internet & $\begin{array}{l}\text { My favorite internet site is Facebook } \\
\text { We also get on Twitter }\end{array}$ & 12 & $21 \%$ \\
\hline & Facebook & $\begin{array}{l}\text { There is this thing called Facebook } \\
\text { You can post everything you do }\end{array}$ & 5 & \\
\hline & Gaming & We play computer games with our friends & 3 & \\
\hline & Other & We like to surf the internet & 2 & \\
\hline Friends & Friends & $\begin{array}{l}\text { We like to hang out with our friends } \\
\text { We talk on phones to our friends } \\
\text { Teens text their friends }\end{array}$ & 20 & $10 \%$ \\
\hline Family & Family & We spend time with family & 8 & $4 \%$ \\
\hline Food & Food & $\begin{array}{l}\text { Most of us stuff our faces with food } \\
\text { After school, we go to Sonic }\end{array}$ & 14 & $7 \%$ \\
\hline Pets/ & Pets/ & Before school, we check chickens for eggs & 10 & $5 \%$ \\
\hline Livestock & Livestock & $\begin{array}{l}\text { I ride horses } \\
\text { Llamas are my favorite animal } \\
\text { I have } 11 \text { dogs. }\end{array}$ & & \\
\hline Other & Other & & 12 & $6 \%$ \\
\hline
\end{tabular}

\section{Facts about Friends/Peers}

The theme of hanging with friends should be cross referenced as closely related to the previous category of facts about teenagers and their role identification, particularly in relation to the recreation and technology themes given above.
Interestingly, this category yielded the lowest number of coded comments when not cross-referencing friend relationships in terms of defining identity. In their more general comments, the participants merely noted that they had friends who they considered strong and good as opposed to peers who caused $a$ lot of drama (see Table 3). Mention of peer pressure 
was also included in this category as co-mingled with the peers who caused drama. This finding is aligned to research indicating that the peer group is a source of conflict for teens and is central to identify formation regardless of geographical location (Reed \& Rossi, 2000).

Table 3

Thematic Categories, Concepts, and Codes Reflecting Facts about Friends

\begin{tabular}{|c|c|c|c|c|}
\hline Concepts & Code Families & Examples of Coded Statements & $\begin{array}{l}\text { Total: } \\
\text { Rate of } \\
\text { Occurrence }\end{array}$ & $\begin{array}{l}\% \text { within } \\
\text { Category }\end{array}$ \\
\hline Friends & Friends & $\begin{array}{l}\text { When it comes to friends, some of us are } \\
\text { kind, caring, and nice } \\
\text { Some friends are funny, shy, outgoing, and } \\
\text { smart }\end{array}$ & 26 & $42 \%$ \\
\hline $\begin{array}{l}\text { Peers (not } \\
\text { friends) }\end{array}$ & $\begin{array}{l}\text { Peers (not } \\
\text { friends) }\end{array}$ & $\begin{array}{l}\text { There are people who cause drama } \\
\text { A lot of us are rude, disrespectful } \\
\text { Some people stab their friends in the backs } \\
\text { In school, there is a lot of peer pressure } \\
\text { When you become a teen, there is a lot of } \\
\text { drama, heartache, no money, and gossip }\end{array}$ & 13 & $68 \%$ \\
\hline
\end{tabular}

\section{Facts about School}

Participants also shared their thoughts on school. Comments in this category fell into two broad concepts: positive comments and negative comments with six codes emerging related to sports, teachers, school spirit and culture, curriculum, rules and regulations, and food (see Table 4).

Table 4

Thematic Categories, Concepts, and Codes Reflecting Facts about School

\begin{tabular}{|c|c|c|c|c|}
\hline Concepts & Code Families & Example Coded Statements & $\begin{array}{c}\text { Total: } \\
\text { Rate of } \\
\text { Occurrence }\end{array}$ & $\begin{array}{c}\% \\
\text { within } \\
\text { category }\end{array}$ \\
\hline \multirow[t]{3}{*}{$\begin{array}{l}\text { School } \\
\text { Positive } \\
\text { (Total) }\end{array}$} & Sports & $\begin{array}{l}\text { Our school is obsessed with sports. } \\
\text { We LOVE to get down and dirty. } \\
\text { Sport events are a BIG high with } \\
\text { everybody }\end{array}$ & 28 & $66 \%$ \\
\hline & Teachers & $\begin{array}{l}\text { All your teachers know you by name (that } \\
\text { can be a good or bad thing!) } \\
\text { We have the most awesome teachers }\end{array}$ & 6 & \\
\hline & $\begin{array}{l}\text { School Spirit } \\
\text { and Culture }\end{array}$ & $\begin{array}{l}\text { Some benefits of going to a small school } \\
\text { is that you have small classes } \\
\text { You still have a variety of kids in your } \\
\text { class } \\
\text { We like small schools } \\
\text { That way we know everybody }\end{array}$ & 10 & \\
\hline \multirow[t]{3}{*}{$\begin{array}{l}\text { School } \\
\text { Negative }\end{array}$} & Curriculum & $\begin{array}{l}\text { School is hard } \\
\text { School is boring } \\
\text { School is not as easy as it looks }\end{array}$ & 11 & $34 \%$ \\
\hline & $\begin{array}{l}\text { Rules and } \\
\text { Regulations }\end{array}$ & $\begin{array}{l}\text { School has too many rules } \\
\text { School starts too early } \\
\text { Not enough time between classes }\end{array}$ & 9 & \\
\hline & Food & The food is bad & 3 & \\
\hline
\end{tabular}


Positive comments included admiration of local sports teams, and great 'school pride,' praising teachers, and a noted appreciation of small schools. In appreciating their schools, the participants noted the small class sizes, knowing all their peers, and having a diverse peer group. These students felt that they knew a lot of 'different sorts of kids' and felt their peers represented a diverse population, even at the second school where the demographic was overwhelming Caucasian. Their definition of diversity hinged primarily on considerations of the perceived talents and interests of their peers (sporty kids, jocks, kids who like art, smart kids).

Negative comments included remarks about the academic demands of school, school strictness in rules and regulation, and comments about cafeteria food quality. The students' protests of school strictness included a large number of comments about school positions on technology usage indicating the participants' desire to keep their phones

\section{Facts about Community}

Finally, student comments on their communities fell into two thematic categories with five codes: positive comments and negative comments (see Table 5). Positive comments included participants' references to specific restaurants they endorsed with Sonic being a front contender in popularity. Participants also positively referenced 'things to do' in their town including specific stores to visit (WalMart) and local festivals or events.

Interestingly, participants made unambiguous references praising the benefits of their small town as opposed to an urban setting. In this vein, they included the benefit of everyone in the community being connected and knowing each other. Ironically, negative comments included statements about lack of privacy as well as remarks indicating there was not much to do in the community and that the community was boring and too safe.

\section{Table 5}

Thematic Categories, Concepts, and Codes Reflecting Facts about Community

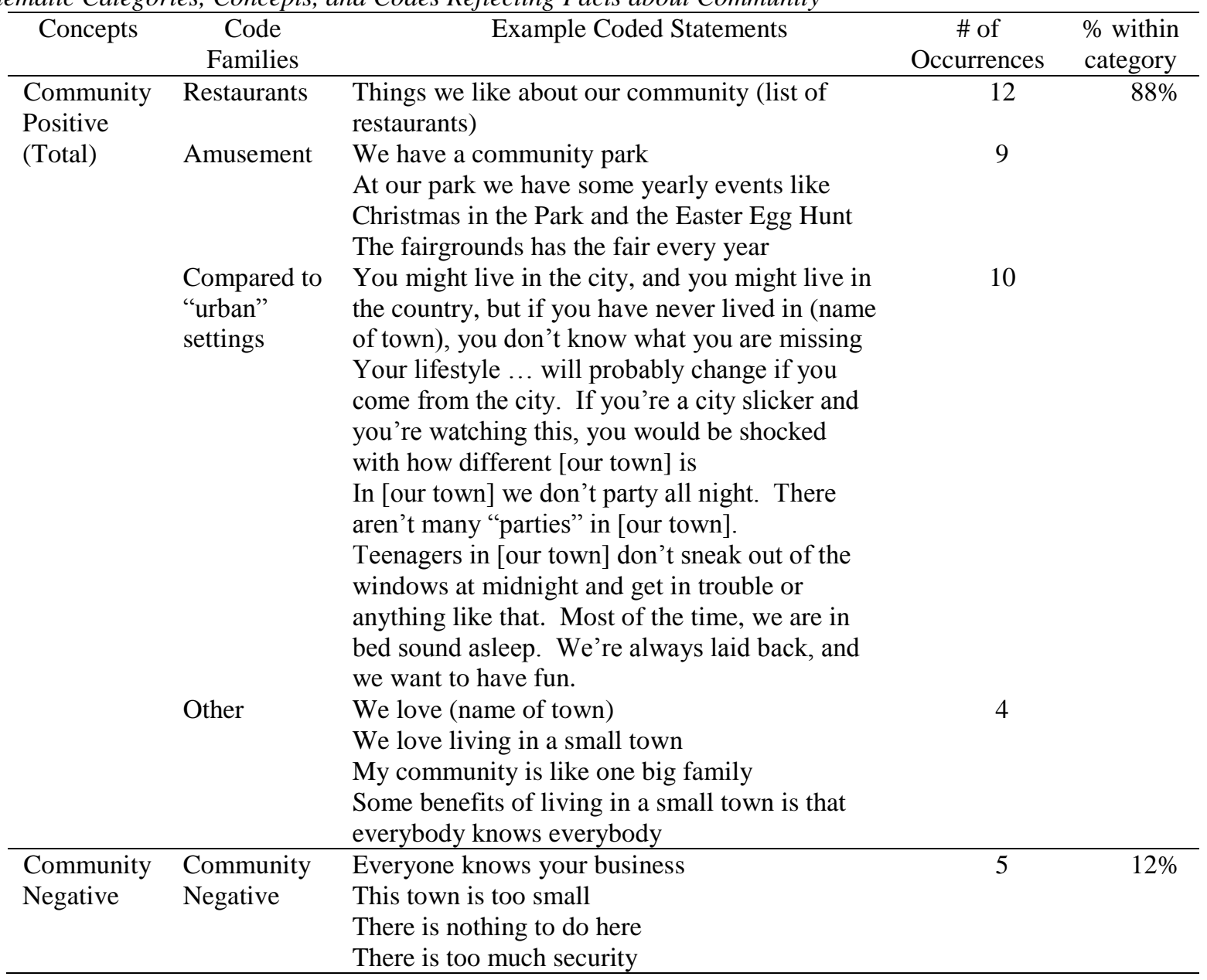




\section{Discussion}

This study examined rural middle school students' narrative inquiry processes as they explored their identity and their local, rural contexts via digital storytelling. The digital stories produced by the participants yielded themes shared across both rural participant communities. While some themes may be posited as unique to a rural population, other themes were quite typical of the adolescent developmental stage regardless of geographical context.

\section{Rural Factors Influencing Perception of Identity}

The predominant theme emerging from the data was the adolescents' focus in their writings on defining their identity. They defined themselves by their recreational activities (movies, shopping, outdoor activities, for example), their role identification (e.g., jock, smart, in the band), their use of technology (texting, Facebook), their friend and family ties, their food preferences, and the presence in their lives of pets and livestock.

Some of these concepts represent typical concerns of this age-group regardless of geographical location (Erikson, 1979; Kroger, 2003, 2006). These concepts include the importance of friends and some of the school specific roles they adopted for themselves as influential in adolescent identity formation. The roles the students adopted included both academic roles (desire to make good grades or simply make it through to the next grade) and non-academic roles (i.e. sports, arts). This finding is aligned with Reed and Rossi's (2000) study which identified that the adolescent search for identity is prevalent regardless of context (urban, suburban, or rural).

The adolescent search for self is not distinctive, but it is reliant on place. In this study, identity was influenced by the students' rural contexts.

One code emergent in the data considered unique to rural settings was the mention of outdoor recreational activities. Corbett (2009) identifies skills unique to rural contexts to include the ability to "build your own shelter, hunt, fish, grow food, cut wood, prepare cooking fires, and live outside grids, systems, and expert controlled mass delivery system" (p. 11). Similarly, Conroy (1997) found that a noteworthy number of rural youths had job aspirations aligned with trade or work related to outdoors activities.

Many of the students, the male students in particular, made specific references to outdoor recreational activities like hunting, fishing, and 4wheeling. While suburban and urban students may also have experiences with similar outdoor activities, it was thought that the prevalence of this theme in this study was an indication of the students' identification with their rural setting.

Additionally, some of the labels the teens used in describing their role identification might be considered uniquely rural, such as "redneck" (someone who works or spends significant time outdoors) or "roper" (someone who participates in rodeo settings). These students appeared to be identifying with the rural nature of their community and were proud to be considered "farm kids." Some of these students openly and proudly identified themselves as "rednecks." Again, this is an identification concept and aligned with the research of Corbett (2009) and Conroy (1997).

Finally, the mention of pets and livestock (chickens, cows, horses, llamas, goats, rabbits, etc.) held some uniquely rural codes. While all teens might be expected to reference pets (dogs, cats, for example), these participants' mention of goats, llamas, chickens, and pigs seemed uniquely rural. Interestingly, mention of livestock was more prevalent in the second participant community, and these students may be seen as attempting to "claim" their rural identity despite their closer location to an urban setting bringing to mind Kelly's (2009) study which references the agency of nostalgia in connecting people to an unexamined myth about 'a way of life.' Again, Conroy's (1997) research is relevant here as is Corbett's (2009) reference to life skills that rural individuals feel are important, to include animals used as a food source.

\section{Rural Factors Influencing Perception of Community}

The influence of the rural contexts on these participants also emerged in the fourth category, facts about community, and, to some extent, in the third results category, facts about school). Comments indicated an awareness of these adolescents of their unique geographical context. Many of the adolescents made comments specifically contrasting their understanding of their community to their vision of the 'big city.' Participants' comments assumed certain stereotypes about big cities as opposed to their rural contexts. They clearly felt that life in a rural setting was superior to life in a city. They also assumed that teens who lived in cities were trouble makers who sneaked around, partied all the time, and joined gangs.

Participants made comments like, "You might live in the city, and you might live in the country, but if you have never lived in (name of town), you don't know what you are missing!" and "In [our town] we don't party all night." "There aren't many parties in [our town]" and "Teenagers in [our town] don't sneak out of the windows at midnight and get in trouble or anything like that. Most of the time, we are in bed sound asleep." 
These findings are aligned with research shared by Lewis and Ketter (2008). In their work with rural teachers, the authors found that these teachers "associated urban youth culture with violence, gangs and sex. By contrast, [the teachers] believed that the lives of their rural students were not overly touched by these realities" (p. 287). These teachers viewed their rural students as innocent while perceiving urban students and culture as ethnic and potentially threatening. In doing so, they cast urban students into the role of "other" and used this sense of other to define identity and set boundaries. While the Lewis and Keith study focused on teachers' perceptions, it is not much of a leap to presume that their students may also share these views.

Overall, the participants in this study seemed to feel that there was an advantage to living in a rural context, and they were proud to differentiate their community as a better place to live. This fits with Kelly's (2009) research into rural contexts as a center of identity, possibility, and interconnection. If students in this study had any desire to leave their communities or to regard other contexts (urban, suburban) as more attractive, they did not share these thoughts in the stories beyond simple comments about their home towns being "too safe" and "everyone knowing your business." Unfortunately, the comments produced by these teens may also represent Kelly's warning about passionate, unexamined attachment leading to a "fierce clinging to places and identities and their deeply embedded and often unexamined myths about a 'way of life"'(p.3). The participants' comments do reflect some deeply engrained and uncritical views about life in rural towns as opposed to life in cities.

\section{Use of Technology to Explore Identity and Context}

The use of digital storytelling in this study was intended as a vehicle to allow the participants to express their views on who they were and where they lived. Certainly traditional writing formats, that is, without technology integration, may have allowed these adolescents to share their perspectives. However, the use of digital storytelling provided some unique advantages to the participants and the study.

First and foremost, digital storytelling allowed these learners to write for an authentic audience and recognize their product as something worth sharing with others interested in their message in a social context (Cope \& Kalantzis, 2000; Gee, 2000; Gruenewald, 2003; New London Group, 1996; O’Brien $\&$ Scharber, 2008). This provided the participants with an expanded sense of writing and of audience. In contrast, a traditional writing assignment (pen and paper) may have been construed as just another school assignment with the teacher as reader/evaluator.
Second, digital storytelling provided participants with a multimodal venue for exploring and communicating issues of identity and community important to them as they shared their insights with an authentic audience. In crafting their stories, the adolescents used both images and narrative thus increasing the power of the messages the adolescents chose to share. The inclusion of images may also have motivated these students to engage in the writing process as they saw themselves producing something more akin to a movie or documentary, which is more appealing than a position paper. Again, these learners are predisposed to receiving and working with visual and media influences (DeVoss, Eidman-Aadahl, \& Hicks, 2010; Kajder, 2010).

Finally, the appeal of technology alone may have been enough to motivate these students to share their stories. The participants' use of technology was a dominant concept in their discussion about teens. The influence of technology on rural adolescents' identity formation and their use of technology to connect to friends was an important finding. These participants were clearly accessing and using technology and they saw technology as essential for communicating connecting to each other.

While participant comments in this category indicate that students are already connected digitally and are already engaged in digital literacies, school support for adolescents' use of these tools to critically examine their own identity and the impact of their rural community appears to be limited. Schools may not be capitalizing on adolescents' existing digital writing practices to aid these learners in exploring issues of identity or community. The technology survey completed by the classroom teachers showed that each classroom associated with this study had limited technology resources and that the teachers involved in the study were not able to easily integrate technology into their instruction. Unfortunately, this finding is aligned with the research (Hawkes, Halverson, \& Brockmueller, 2002).

Allowing students to explore identity in their rural contexts may be critical to their development of identity and voice and may either promote student identification with their community or disassociate students from their community. Kelly (2009) cautions that rural places are premised on a loss paradigm; yet, participants in this study used literacy to claim community and to refute this loss paradigm in contrast to the research findings (Corbett, 2009; Corbett \& Vibert, 2010; Hardré, Sullivan, \& Crowson 2009), while at the same time showing evidence of an uncritical attachment to place (Kelly, 2009). So while the digital storytelling application used in this study may have allowed students opportunity to explore their 
own narratives, they did not critically examine their contexts.

\section{Limitations}

This study is limited by its inclusion of only two schools in a fairly restricted geographical area. In addition, while the intent of using of digital stories should have conveyed the message that the students were writing for an authentic audience, more could have been done to send students the message that they were writing for an authentic audience and rather than for a grade. Also, students could have been supported in producing individual stories as opposed to groupproduced stories.

Additional data could have been collected around this study design to include field notes documenting the participants' work in process, artifacts of the students' work in process (brainstorm maps, drafts). Finally, an analysis of the images chosen by the students could have been analyzed for their message and impact.

\section{Conclusions}

This study examined adolescent students' exploration of identity and community. The use of digital storytelling with adolescents provided a particularly rich opportunity for these students to

\section{References}

Bogdan, R. C., \& Biklen, S. K. (2003). Qualitative research for education: An introduction to theories and methods $\left(4^{\text {th }}\right.$ ed.). Boston, MA: Pearson Education.

Lambert, J. (2012). Center for digital storytelling. Retrieved from http://www.storycenter.org/

Cope, B. \& Kalantzis, M. (Eds.). (2000). Multiliteracies: Literacy learning and the design of social futures. London: Routledge.

Corbett, M. (2009). Rural schooling in mobile modernity: Returning to the places I've been. Journal of Research in Rural Education, 24(7), 113. Retrieved from http://jrre.psu.edu/articles/247.pdf

Corbett, M. \& Vibert, A. (2010). Curriculum as a safe place: Parental perceptions of new literacies in a rural small town school. Canadian Journal of Educational Administration and Policy, 114, 6-24

Conroy, C. A. (1997, March). Predictors of occupational choice among rural youth: Implications for career education and development programming. Paper presented at the meeting of the American Educational Research Association, Chicago, IL. explore the areas of inquiry unique to their age group as determined through grounded theory analysis of the participants' digital story products.

Study findings indicate that the rural nature of the participants' communities had a significant impact on their identity formation in particular with respect to specific recreational activities and identity roles. Participants also were keenly aware of their rural contexts. While participants made some comments decrying the limitations of rural schools and towns, the main focus was on the positive aspects of school and community, which they viewed as places of support and connectedness.

Findings from this study also indicate that rural students are already engaged in digital literacy practices. However, school support for adolescents' use of these tools may not be capitalizing on students' outside-school digital writing practices. Technology should be considered implicit in adolescent identity development and should be used to promote student exploration of identity and context. These tools provide students with means to assess and acquire skills necessary to compete in current global and technological climates. As such, this study supports students' use of digital writing to explore identity, to examine their rural contexts, and to further their literacy development through technology-supported practices.

Creswell, J. W. (2002). Research design: Qualitative, quantitative, and mixed methods approaches (2nd ed.). Thousand Oaks, CA: Sage.

DeVoss, D. N., Eidman-Aadahl, E., \& Hicks, T. (2010). Because digital writing matters: Improving student writing in online and multimedia environments. San Francisco, CA: Jossey-Bass.

York, NY: W.W. Norton.

Gee, J. P. (2005). An introduction to discourse Analysis Theory and Method ( $2^{\text {nd }}$ ed.). New York: Routledge.

Gee, J. P. (2000). New people in new worlds: Networks, the new capitalism and schools. In B. Cope \& M. Kalantzis (Eds.), Multiliteracies (pp. 43-68). London \& New York: Routledge.

Glaser, B. G., \& Strauss, A. L. (1967). The discovery of grounded theory: Strategies for qualitative research. Chicago, IL: Aldine.

Graves, B. (2010). The collision of athletics \& consolidation. School Administrator, 67(5), 24-29.

Gruenewald, D. A. (2003). The best of both worlds: A critical pedagogy of place. Educational Researcher. 32(4), 3-12. 
Hawkes, M., Halverson, P., \& Brockmueller, B. (2002). Technology facilitation in the rural school: An analysis of options. Journal of Research in Rural Education, 17(3), Retrieved from http://www.jrre.psu.edu/articles/v17,n3,p162170,Hawkes,Halverson,Brockmueller.pdf

Hardré, P., Sullivan, D., \& Crowson, H. (2009). Student characteristics and motivation in rural high schools. Journal of Research in Rural Education, 24(16). Retrieved from http://jrre.psu.edu/articles/24-16.pdf

Howley, A., \& Howley, C. (2006). Small schools and the pressure to consolidate. Educational Policy Analysis Archives, 14(10), 1-23.

Kajder, S. (2010). Adolescencents and digital literacies: Learning alongside our students. Urbana, IL: National Council of Teachers of English.

Kelly, U. A. (2009). Learning to lose: Rurality, transience, and belonging (a companion to Michael Corbett). Journal of Research in Rural Education, 24(11). Retrieved from http://jrre.psu.edu/articles/24-11.pdf

Erikson, E. H. (1979). Dimensions of a new identity: The Jefferson Lectures in the Humanities. New

Kerpelman, J. L., Pittman, J. F., \& Lamke, L. K. (1997). Toward a microprocess perspective on adolescent identity development: An identity control theory approach. Journal of Adolescent Research, 12(3), 325-346.

Kroger, J. (2003, 2006). Identity development during adolescence. In G. R. Adams \& M. D. Berzonsky (Eds.), Blackwell handbook of adolescence (pp. 205-226). Malden, MA: Blackwell.

Lewis, C. \& Ketter, J. (2008). Encoding youth: Popular culture and multicultural literature in a rural context. Reading and Writing Quarterly, 24(3), 283-310.

Meeus, W., Iedema, J., Helson, M., \& Volleberg, W. (1999). Patterns of adolescent identity development: Review of literature and longitudinal analysis. Developmental Review, 19(4), 419-461.
Miller, M. (2010). An investigation of perceived anxiety toward new software technologies among teachers in a Mississippi rural school district. ProQuest Dissertations and Theses. Retrieved from http://gradworks.umi.com/33/98/3398540.html

The National Center for Educational Statistics (2007). Status of education in rural America. Retrieved from http://nces.ed.gov/pubs2007/2007040.pdf

New London Group. (1996). A pedagogy of multiliteracies: Designing social futures. Harvard Educational Review, 66(1), 60-92.

Nitta, K., Holley, M., \& Wrobel, S. (2010). A phenomenological study of rural school consolidation. Journal of Research in Rural Education, 25(2), 1-19. Retrieved from http://jrre.psu.edu/articles/25-2.pdf.

O'Brien, D. \& Scharber, C. (2008). Digital literacies, Journal of Adolescent \& Adult Literacy, 52(1), 6668.

Ohler, J. (2008). Digital storytelling in the classroom. Thousand Oaks, CA: Corwin Press.

Reed, D. F. \& Rossi, J. A. (2000). "My three wishes": Hopes, aspirations, and concerns of middle school students. The Clearing House, 73(3), 141-44.

Schafft, K. A., Alter, T. R. \& Bridger, J. C. (2006). Bringing the community along: A case study of a school district's information technology rural development initiative. Journal of Research in Rural Education 21(8). Retrieved from http://www.jrre.psu.edu/articles/21-8.pdf

Strauss, A., \& Corbin, J. (1990). Basics of qualitative research: Grounded theory procedures and techniques. Newbury Park, CA: Sage.

Strauss, A., \& Corbin, J. (1994). Grounding theory methodology: An overview. In Handbook of qualitative research, N. Denzin \& Y. Lincoln (eds.), pp. 273-285. Thousand Oaks, CA: Sage.

Wood, A.F. \& Smith, M.J. (2010). Online communication: Linking technology, identity, and culture. Mahwash, NJ: Lawerence Erlbaum.

\section{About the author: \\ Donna Wake teaches at the University of Central Arkansas (Conway, AR) and at La Salle University (Philadelphia, PA). She has also taught English Language Arts in Philadelphia, PA and in Jackson, MS. Her research interests include critical literacy, multiliteracies, narrative inquiry, and teacher education reform.}

